\title{
Influence of Environmental Factors on the Presence and Severity of Molar Incisor Hypomineralization
}

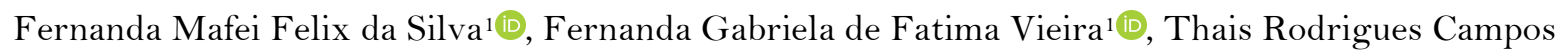

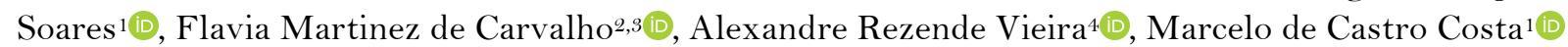

${ }^{1}$ Department of Paediatric Dentistry and Orthodontics, School of Dentistry, Federal University of Rio de Janeiro, Rio de Janeiro, RJ, Brazil.

${ }^{2}$ Laboratory of Congenital Malformation Epidemiology, Oswaldo Cruz Institute, Rio de Janeiro, RJ, Brazil.

${ }^{3}$ Latin American Collaborative Study of Congenital Malformations, National Institute of Population Medical Genetics, Rio de Janeiro, RJ, Brazil.

${ }^{4}$ Department of Oral Biology, School of Dental Medicine, University of Pittsburgh, PA, United States of America.

Correspondence: Marcelo de Castro Costa, Rua Professor Rodolpho Paulo Rocco, 325, Faculdade de Odontologia, Cidade Universitária, Ilha do Fundão, Rio de Janeiro, RJ, Brazil.21941-971. E-mail: pttpo2009@yahoo.com.br

Academic Editor: Alidianne Fábia Cabral Cavalcanti

Received: 13 June 2020 / Review: 19 January 2021 / Accepted: 29 March 2021

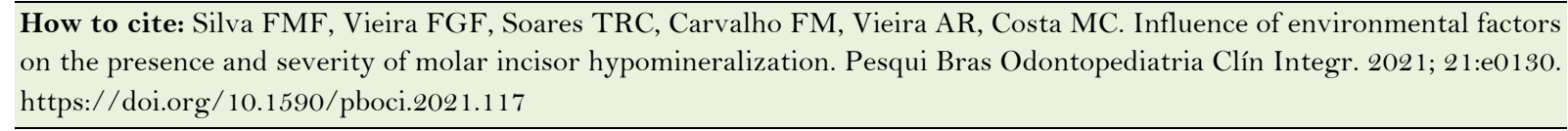

\begin{abstract}
Objective: To assess the association between environmental factors during pregnancy and early childhood with the presence and severity of Molar Incisor Hipomineralization (MIH). Material and Methods: This cross-sectional study was conducted with 120 patients between 7 and 14 years of age. MIH was evaluated according to EAPD criteria. Data collected included the child's medical history and the mother's health. Chi-square and logistic regression were performed to determine any statistical evidence of the environmental factors, with the significance level set at $5 \%$. Results: The participants were divided into groups with MIH $(n=60)$ and without MIH $(n=60)$, with average ages of $9.9( \pm 1.9)$ and $9.7( \pm 1.7)$ years, respectively. There was a statistically significant difference between intercurrences during pregnancy $(\mathrm{OR}=3.55$; IC95\%=1.35-10.57) and medication taken by the child $(\mathrm{OR}=3.01$; IC95\%=1.74-8.42) and the presence of MIH. In addition, other variables were also associated with the MIH $(\mathrm{p} \leq 0.05)$. However, there was no association with variables and degree of MIH severity ( $p>0.05)$. Conclusion: The use of medications in childhood and complications during pregnancy can be association to the presence of MIH. However, these factors do not interaction to MIH severity.
\end{abstract}

Keywords: Tooth Abnormalities; Dental Enamel Hypoplasia; Child; Tooth Demineralization. 


\section{Introduction}

Developmental enamel defects have been the most widely studied dental anomaly over the past few years [1,2]. Molar incisor hypomineralization (MIH) is an example of these defects, which affect one to four permanent molars and is often associated with permanent incisors [3,4]. In addition, hypomineralization lesion has been associated with permanent canines and primary second molars called Hypomineralized Second Primary Molars (HSPMs) [5,6]. The prevalence of this condition varies considerably in different parts of the world, ranging from 2.8 to $44 \%$ [7-9].

One of the main characteristics of MIH is enamel porosity and demarcated opacity, which may vary from white/yellowish to brown [4]. Yet another characteristic is that MIH can undergo post-eruptive enamel breakdown due to masticatory forces [4,10], resulting in hypersensitivity of the affected teeth, which makes oral hygiene difficult to perform and may result in caries lesions [10,11]. It can also cause aesthetic problems that may affect an individual's quality of life $[12,13]$. Owing to the many consequences of MIH to individuals, periodic dental appointments are important to help management hypomineralization lesions [14].

Ever since the criteria for MIH were developed, there has been a great discussion in the literature about its possible etiological factors [15]. It is already known that genes involved in amelogenesis influence the etiology of developmental enamel defects $[15,16]$. In addition, risk factors associated with the use of medication and severe infections in the pre- and perinatal period or in childhood may lead to the development of $\mathrm{MIH}[17,18]$. Although there is evidence that environmental and genetic [16,18] factors may be associated with this condition, there is still no conclusive relevant data. Greater knowledge concerning the etiological factors and clinical characteristics are essential to allow its management and future prevention. Thus, the purpose of this study was to assess the association between environmental factors during pregnancy and early childhood with the presence and severity of MIH.

\section{Material and Methods}

Ethical Clearance

This study was approved by the Committee for Ethics in Research of the Clementino Fraga Filho University Hospital (Protocol No. 44598514.7.00005257). All parents/caregivers read and signed an assent form. In addition, child/adolescent included in this study also signed an assent form.

\section{Study Design}

This cross-sectional study was conducted at the Pediatric Dental Clinics of the Universidade Federal do Rio de Janeiro between July 2015 and Abril 2017. A sample consisting of 120 patients of both sexes, between 7 and $14(9.94 \pm 1.67)$ years of age, was recruited during this period.

The groups were paired by sex and divided into patients with MIH $(n=60)$ and those without MIH $(n=60)$. The inclusion criteria for this study were patients with fully erupted first permanent molars. The exclusion criteria for both groups were children with syndromes, enamel defects (hypoplastic lesions, fluorosis, amelogenesis imperfecta) and patients undergoing orthodontic treatment.

Training and Calibration Exercise

A calibration exercise was carried out in two stages to assess the intra- and inter-examiner reliability for MIH: theorical and practical activities. The theorical stage consisted of a discussion of the MIH criteria diagnosis among the study technicians. A professor of pediatric dentistry (MCC), who is the gold standard in 
the area, coordinated this stage by instructing the examiner on how to perform the clinical examination. The practical stage was performed with 20 clinical images containing several dental enamel alterations, including fluorosis, hypoplasia, amelogenesis imperfecta and $\mathrm{MIH}$ with different locations, discoloration and breakdown. Also included image without enamel defects. After an interval of two weeks, the images were reevaluated and Kappa statistics were applied to measure intra-examiner, with values of 0.88 and 0.89 , respectively.

\section{Data Collection}

The information collected in this study was obtained from face-to-face interviews with the children's guardians through a medical record. The health aspects were recorded through anamnesis, including demographic data (child's age, sex, place of birth, residence), and information on the mother's health during pregnancy (medications taken, severe infections and complications during childbirth), and the child's medical history (medications taken, severe infections, high fever, asthma, bronchitis).

\section{Clinical Examination}

The clinical examination was performed in the dental chair, where the teeth were examined under artificial light, with a mirror and a probe, after prophylaxis. The MIH diagnosis was based on the criteria established by the European Academy of Paediatric Dentistry (EAPD) [2]. The severity of MIH was recorded according to Lygidakis et al. [19] as mild when the tooth presented demarcated opacities, without enamel breakdown, occasional sensitivity to external stimuli (Figure 1A and 1B), and severe when the tooth showed enamel breakdown, caries, restoration and persistent/spontaneous hypersensitivity (Figure 1C).

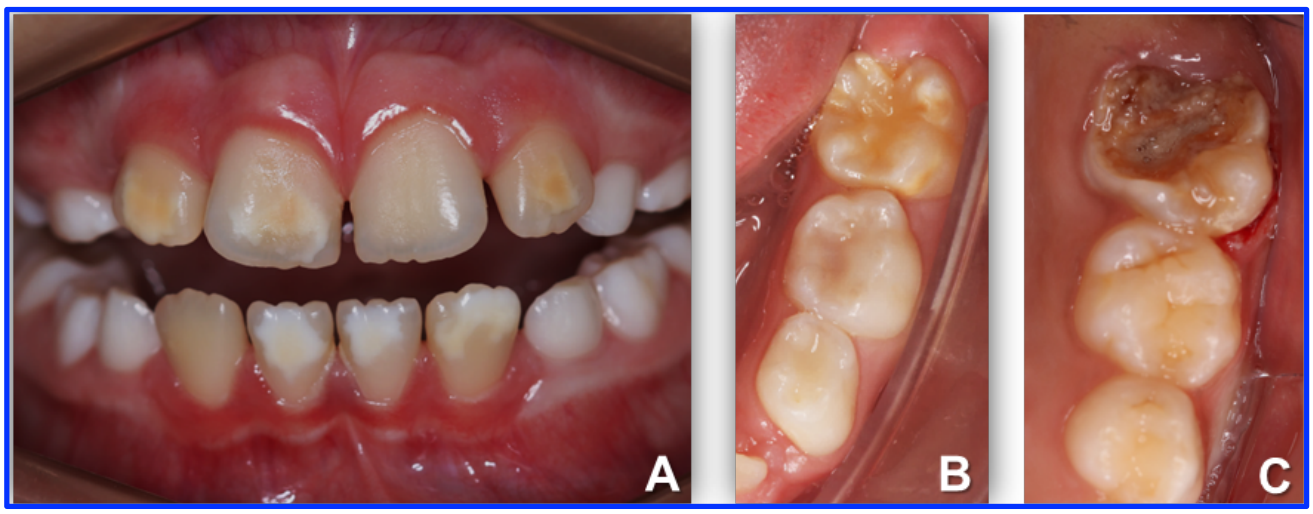

Figure 1. A) Incisors with mild MIH; B) First permanent molar presenting opacity without loss of structure; C) First permanent molar with opacity and loss of structure.

Statistical Analysis

The data were analyzed using SPSS software version 21.0 (Statistical Package for Social Sciences, SPSS, Chicago, IL). Student's t-test was performed to check the average age between groups with and without MIH (SD). Chi-square test was applied to determine the associations between environmental factors and MIH, and to assess the degree of MIH severity on environmental factors $(\mathrm{p}<0.05)$. Univariate regression and Odds ratio was performed to assess the relationships and chances between the variables (risk factors during pregnancy period and child first years of life) in relation to the groups (with and without MIH) $(\mathrm{p}<0.05)$.

\section{Results}


All the subjects recruited were included in the study. The participants were divided into children with MIH (n=60) and without MIH $(\mathrm{n}=60)$, with average ages of $9.9( \pm 1.9)$ and $9.7( \pm 1.7)$ years, respectively (Table 1). A total of 283 teeth were affected by MIH, 30.74\% $(n=87)$ were first permanent maxillary molars, $28.26(n=$ 80) were first permanent mandibular molars, 25.8\% $(n=73)$ were permanent maxillary incisors, and $15.5 \%$ $(\mathrm{n}=43)$ were permanent mandibular incisors.

Logistic regression showed that MIH was statistically associated with complications during the gestational period (serious infections/systemic diseases) $(\mathrm{OR}=3,55 ; 95 \% \mathrm{CI}=1.35-10.57, \mathrm{p}=0.014)$ and with children using medication $(\mathrm{OR}=3.01 ; 95 \% \mathrm{CI}=1.74-8.42, \mathrm{p}=0.019)$. In addition, other variables were also associated with the MIH (Table 1).

Table 1. Interaction between environment factors and Molar Incisor Hypomineralization (MIH).

\begin{tabular}{|c|c|c|c|c|c|c|}
\hline \multirow[b]{2}{*}{ Variables } & & \multicolumn{2}{|c|}{ MIH } & \multirow[t]{2}{*}{ p-value } & \multirow[t]{2}{*}{ OR (95\% C.I) } & \multirow[t]{2}{*}{ p-value ${ }^{* * *}$} \\
\hline & & No & Yes & & & \\
\hline \multirow{2}{*}{ Degree of MIH Severity } & Mild & - & $35(58.3)$ & - & - & - \\
\hline & Severe & - & $25(41.7)$ & & & \\
\hline \multirow[t]{2}{*}{ Sex } & Female & $30(50.0)$ & $30(50.0)$ & - & - & - \\
\hline & Male & $30(50.0)$ & $30(50.0)$ & & & \\
\hline Mean Age (SD) & & $9.7(1.7)$ & $9.9(1.9)$ & $0.544^{* *}$ & & \\
\hline \multirow[t]{2}{*}{$\begin{array}{l}\text { Intercurrences During Pregnancy and in } \\
\text { Early Childhood }\end{array}$} & Yes & $14(23.3)$ & $32(53.3)$ & 0.001 & $3.75(1.74-8.42)$ & 0.001 \\
\hline & No & $46(76.7)$ & $28(46.7)$ & & & \\
\hline \multirow[t]{2}{*}{$\begin{array}{l}\text { Medication Taken in Early Childhood } \\
\text { (o-3 years) }\end{array}$} & Yes & $8(13.3)$ & $19(31.7)$ & 0.029 & $3.01(1.23-7.95)$ & 0.019 \\
\hline & No & $52(86.7)$ & $41(68.3)$ & & & \\
\hline \multirow[t]{2}{*}{ Use of Medication During Pregnancy } & Yes & $7(11.7)$ & $9(15.0)$ & 0.788 & $1.33(0.46-3.99)$ & 0.592 \\
\hline & No & $53(88.3)$ & $51(85.0)$ & & & \\
\hline \multirow[t]{2}{*}{$\begin{array}{l}\text { Intercurrences During Pregnancy - Severe } \\
\text { Infections/Systemic Diseases }\end{array}$} & Yes & $6(10.0)$ & $17(28.3)$ & 0.020 & $3.55(1.35-10.57)$ & 0.014 \\
\hline & No & $54(90.0)$ & $43(71.7)$ & & & \\
\hline \multirow[t]{2}{*}{ Complications During Childbirth } & Yes & $5(8.3)$ & $14(23.3)$ & 0.045 & $3.34(1.18-10.99)$ & 0.030 \\
\hline & No & $55(97.7)$ & $46(76.7)$ & & & \\
\hline
\end{tabular}

*Chi-square $(\mathrm{p}<0.05)$; *** Student's t-test $(\mathrm{p}<0.05)$; ***** Univariate Regression $(\mathrm{p}<0.05)$.

Regarding the prevalence of MIH severity, most participants $(58.3 \%$; $=35)$ had teeth affected by mild MIH. According to the risks facts (during pregnancy and first year's child life), there was no interaction of the variables tested on the degree of MIH severity $\mathrm{p} \geq 0.05$ (Table 2).

Table 2. Relationship between MIH severity and environmental factors.

\begin{tabular}{lcccc}
\multicolumn{1}{c}{ Variables } & \multicolumn{4}{c}{ MIH } \\
& & Mild (N = 35) & Severe (N =25) & p-value* \\
& & $\mathrm{N}(\%)$ & $\mathrm{N}(\%)$ & \\
\hline Medication Taken in Early Childhood (0-3 Years) & Yes & $8(42.1)$ & $11(57.9)$ & 0.146 \\
Intercurrences During Pregnancy and in Early Childhood & Ye & $27(65.9)$ & $14(34.1)$ & \\
& No & $17(53.1)$ & $15(46.9)$ & 0.540 \\
Use of Medication During Pregnancy & Yes & $6(66.7)$ & $3(33.3)$ & 0.722 \\
Intercurrences During Pregnancy & No & $29(56.9)$ & $22(43.1)$ & \\
& Yes & $12(70.6)$ & $5(29.4)$ & 0.260 \\
Complications During Childbirth & No & $23(53.5)$ & $20(46.5)$ & \\
& Yes & $6(42.9)$ & $8(57.1)$ & 0.302 \\
\hline * & No & $29(63.0)$ & $17(37.0)$ & \\
\hline
\end{tabular}

*Chi-square $(\mathrm{p}<0.05)$. 


\section{Discussion}

Several different etiological factors have been identified as causing MIH. Some environmental factors and genes involved in enamel formation are associated with $\mathrm{MIH}$ [17,20]. In addition, the literature reports that the use of medication and systemic diseases during pregnancy and the first years of a child's life are potential etiological risk factors for $\mathrm{MIH}[17,18]$.

This study found an association between MIH and complications during childbirth or during pregnancy. These findings confirm previous studies that also observed an association of MIH with these variables [21,22]. Another significant variable in our study was the association of MIH with the use of medication in the first years of child's life, and this may be related to the period of formation of the permanent incisors and first molars that begins around the intrauterine life and extends to the third year of life. Theoretically, the use of medications in the first year of life has been reported with the presence of MIH [17]. On the other hand, Allazam et al. [23] reported an association between MIH and type of medication at any time in early childhood. The information collected in this study was obtained from face-to-face interviews with the children's guardians. Although there is evidence suggesting that studies using parent recall provide inadequate evidence, this inadequacy may be related to recall bias. In contrast, our study was mostly comprised of mothers, who are typically better at recalling information related to the early life of their children and their pregnancy [24].

Regarding the degree of severity, there was no association of these risk factors (interferences during pregnancy, complications at childbirth and medication taken in pregnancy and childhood) with MIH. This may be attributed to the assessment of predominantly mild MIH made by the above study. Moreover, their results lead us to suppose that the degree of MIH severity is related to genetic inheritance, mainly in relation to characteristics of MIH-affected teeth (tooth color, loss of structure) [25,26].

Among the limitations of the present study are the large gaps between the ages of the children. This made it difficult for the interviewees to answer many questions on the questionnaire. The suggestion is that studies with children from 7 to 10 years old allow a more accurate collection of information. In contrast, this study includes careful data collection in relation to environmental factors (prenatal and postnatal), and most of the interviewed were composed of mothers who were providing more consistent information. Another positive aspect of this study was clinical aspects of MIH, determined by experience pediatric 'dentist. These points increase the confidence in the results obtained in this study.

MIH may be a multifactorial condition. More than one etiological factor can determine its occurrence, especially complications in pregnancy and medication used during the first years of a child's life. These results suggested that MIH may be influenced by environmental factors; however, the genetically effect cannot be underestimated. Longitudinal studies are needed to evaluate how environmental and genetic factors influences MIH in the long term.

\section{Conclusion}

This study suggests that environmental facts, such as the use of medications in childhood and complications during pregnancy, can trigger the development of MIH.

\section{Authors' Contributions}

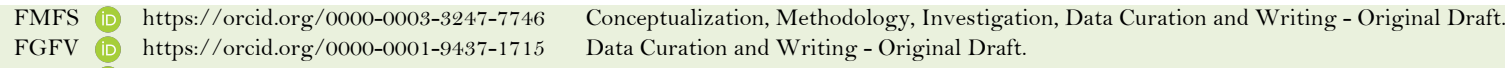

FGFV (iD) https://orcid.org/0000-0001-9437-1715 Data Curation and Writing - Original Draft.

TRCS (D) https://orcid.org/0000-0001-8544-0627 Methodology and Formal Analysis. 
FMC (D) https://orcid.org/0000-0003-2617-9689 Formal Analysis and Writing - Review and Editing.

ARV (iD https://orcid.org/0000-0003-3392-6881 Formal Analysis, Writing - Review and Editing and Supervision.

MCC (iD https://orcid.org/oooo-0003-2192-1960 Conceptualization, Methodology, Data Curation, Writing - Review and Editing and Supervision.

All authors declare that they contributed to critical review of intellectual content and approval of the final version to be published.

\section{Financial Support}

This study was funded in part by the Coordenação de Aperfeiçonamento Pessoal de Nivel Superior - Brasil (CAPES) - Finance Code O0 1 and Fundação de Amparo à Pesquisa do Estado do Rio de Janeiro - FAPERJ, registration no. E-26/201.745/2019.

\section{Conflict of Interest}

The authors declare no conflicts of interest.

\section{Data Availability}

The data used to support the findings of this study can be made available upon request to the corresponding author.

\section{References}

[1] Chauhan D, Chauhan T. Prevalence of developmental defects of enamel in mixed and permanent dentition of 9 and 12 year old children of Himachal Pradesh, India: A cross sectional study. Int J Health Allied Sci 2013; 2(3):185-8.

[Q] Mejía JD, Restrepo M, González S, Álvarez LG, Santos-Pinto L, Escobar A. Molar incisor hypomineralization in Colombia: prevalence, severity, and associated risk factors. J Clin Pediatr Dent 2019; 43(3):185-9. https://doi.org/10.17796/1053-4625-43.3.7

[3] Jälevik B. Prevalence and diagnosis of molar-incisor hypomineralisation (MIH): a systematic review. Eur Arch Paediatr Dent 2010; 11(2):59-64.

[4] Weerheijm KL, Duggal M, Majáre I, Papagiannoulis L, Koch G, Martens HC, et al. Judgement criteria for molar incisor hypomineralisation (MIH) in epidemiologic studies: a summary of the European meeting on MIH held in Athens, 2003. Eur J Paediatr Dent 2003; 4(3):110-3.

[5] Schmalfuss A, Stenhagen KR, Tveit AB, Crossner CG, Espelid I. Canines are affected in 16-year-olds with molarincisor hypomineralisation (MIH): an epidemiological study based on the Tromsø study: "Fit Futures". Eur Arch Paediatr Dent 2016; 17(2):107-13. https://doi.org/10.1007/s40368-015-0216-6

[6] Elfrink ME, Ten Cate JM, Jaddoe VW, Hofman A, Moll HA, Veerkamp JS. Deciduous molar hypomineralization and molar incisor hypomineralization. J Dent Res 2012; 91(6):551-5. https://doi.org/10.1177/0022034512440450

[7] Rodrigues FCN, Ribeiro PHB, Thomaz ÉBAF, Lima GQT, Neves PAM, Ribeiro CCC. Molar-Incisor hypomineralization in schoolchildren of Sao Luis, Brazil, Maranhao: Prevalence and associated factors. Pesqui Bras Odontopediatria Clín Integr 2015; 15(1):271-8. https://doi.org/10.4034/PBOCI.2015.151.29

[8] Hernandez M, Boj JR, Espasa E. Do we really know the prevalence of MIH? J Clin Pediatr Dent 2016; 40(4):259-63. https://doi.org/10.17796/1053-4628-40.4.259

[9] Zhao D, Dong B, Yu D, Ren Q, Sun Y. The prevalence of molar incisor hypomineralization: evidence from 70 studies. Int J Paediatr Dent 2018; 28(2):170-179. https://doi.org/10.1111/ipd.12323

[10] Da Costa Silva CM, Jeremias F, Souza JF, Cordeiro RCL, Santos Pinto L, Zuanon ACC. Molar incisor hypomineralization: prevalence severity and clinical consequences in Brazilian children. Int J Paediatr Dent 2010; 20(6):426-34. https://doi.org/10.1111/j.1365-263X.2010.01097.x

[11] Raposo F, de Carvalho Rodrigues AC, Lia EN, Leal SC. Prevalence of hypersensitivity in teeth affected by molarincisor hypomineralization (MIH). Caries Res 2019; 53(4):424-430. https://doi.org/10.1159/000495848

[12] Leal SC, Oliveira TRM, Ribeiro APD. Do parents and children perceive molar-incisor hypomineralization as an oral health problem? Int J Paediatr Dent 2017; 27(5):372-37. https://doi.org/10.1111/ipd.12271

[13] Da Silva FMF, Cruz CV, Leal L, de Castro Costa M. Aesthetic perception and psychological impact of molar-incisor hypomineralisation among patients and parents. Dentistry 3000 2019; 7(1):13-20. https://doi.org/10.5195/d3000.2019.90

[14] Ozgül BM, Saat S, Sönmez H, Oz FT. Clinical evaluation of desensitizing treatment for incisor teeth affected by Molar-Incisor Hypomineralization. J Clin Pediatr Dent 2013; 38(2):101-5.

[15] Vieira AR, Kup E. On the etiology of molar-incisor hypomineralization. Caries Res 2016; 50(2):166-169. https://doi.org/10.1159/000445128

[16] Jeremias F, Ricardo AG, Pierre JF, Souza CMB, Fragelli MRLS, Finoti DG, et al. Family-based genetic association for molar-incisor hypomineralization. Caries Res 2016; 50(3):310-8. https://doi.org/10.1159/000445726

[17] Laisi S, Ess A, Sahlberg C, Arvio P, Lukinmaa PL, Alauusua S. Amoxicillin may cause molar incisor hypomineralization. J Dent Res 2009; 88(2):132-6. https://doi.org/10.1177/0022034508328334

[18] Alaluusua S. Aetiology of molar-incisor hypomineralisation: A systematic review. Eur Arch Paediatr Dent 2010; 11(2):53-8. https://doi.org/10.1007/BFo3262713 
[19] Lygidakis NA, Wong F, Jalevik B, Vierrou AM, Alaluusua S, Espelid I. Best clinical practice guidance for clinicians dealing with children presenting with Molar-Incisor-Hypomineralisation (MIH): An EAPD policy document. Eur Arch Paediatr Dent 2010; 11(2):75-81. https://doi.org/10.1007/BF03262716

[20] Jedeon K, Houari S, Loiodice S, Thuy TT, Le Normand M, Berdal A, Babajko S. Chronic exposure to bisphenol A exacerbates dental fluorosis in growing rats. J Bone Miner Res 2016; 31(11):1955-66. https://doi.org/10.1002/jbmr.2879

[21] Whatling R, Fearne JM. Molar incisor hypomineralization: a study of aetiological factors in a group of UK children. Int J Paediatr Dent 2008; 18(3):155-62. https://doi.org/10.1111/j.1365-263X.2007.00901.x

[22] Kuscu O, Caglar E, Sandalli N. The prevalence and aetiology of molar-incisor hypomineralisation in a group of children in Istanbul. Eur J Paediatr Dent 2008; 9(3):139-44.

[23] Allazzam SM, Alaki SM, El Meligy OAS. Molar incisor hypomineralization, prevalence, and etiology. Int J Dent 2014; 2014:234508. https://doi.org/10.1155/2014/234508

[24] Rice F, Lewis A, Harold G, van den Bree M, Boivin J, Hay DF, et al. Agreement between maternal report and antenatal records for a range of pre and perinatal factors: the influence of maternal and child characteristics. Early Hum Dev 2007; 83(8):497-504. https://doi.org/10.1016/j.earlhumdev.2006.09.015

[25] Fagrell TG, Ludvigsson J, Ullbro C, Lundin S-A, Koch G. Aetiology of severe demarcated enamel opacities - an evaluation based on prospective medical and social data from 17,000 children. Swed Dent J 2010; 35(2):57-67.

[26] Vieira AR, Manton DJ. On the variable clinical presentation of molar-incisor hypomineralization. Caries Res 2019; 53(4):482-488. https://doi.org/10.1159/000496542 